\title{
PERUBAHAN PERILAKU PETANI TERHADAP PEMANFAATAN URIN SAPI SEBAGAI PUPUK ORGANIK CAIR DI KELOMPOK TANI NGUDI LUHUR DESA PANDEAN KECAMATAN NGABLAK
}

\author{
Iing Damayanti, Sunarsih, Sucipto
}

\begin{abstract}
ABSTRAK
Penelitian dilaksanakan di Kelompok Tani Ngudi Luhur, Desa Pandean, Kecamatan Ngablak pada tanggal 5 Maret 2018 sampai dengan tanggal 30 April 2018. Pennelitian ini bertujuan untuk mengetahui perubahan perilaku anggota Kelompok Tani Ngudi Luhur dalam pembuatan pupuk organik cair urin sapi

Metode penelitian ini menggunakan pendekatan kelompok dan pendekatan perorangan dan pengambilan sampel yang digunakan adalah metode sensus sebanyak 30 responden. Analisis yang digunakan adalah analisis deskriftif comperatif yaitu membandingkan perubahan perilaku anggota kelompok tani sebelum penyuluhan dan sesudah penyuluhan.

Hasil penelitian menunjukkan bahwa setelah dilakukan penyuluhan di Kelompok Tani Ngudi Luhur pada aspek pengetahuan dalam kategori tahu dengan rata-rata 37,40, aspek sikap kategori setuju dengan rata-rata 26,70, aspek keterampilan dalam kategori terampil dengan rata-rata 14,37 dan perubahan perilakunya sebelun dilakukan penyuluhan dalam kategori rendah sebesar 48,43 setelah dilakukan penyuluhan menjadi 78,46 dalam kategori tinggi.

Evaluasi kegiatan penyuluhan untuk mengetahui perubahan perilaku petani dengan menghitung efektivitas penyuluhan (EP) dan efektivitas perubahan perilaku (EPP) mengacu pada Ginting (1993), disimpulkan bahwa pada aspek pengetahuan EP sebesar $74,80 \%$ yang berarti efektif EPP sebesar 51,85\% berarti cukup efektif, aspek sikap EP $76,28 \%$ berarti efektif sedangkan EPP sebesar 52,21\% berarti cukup efektif, aspek keterampilan EP sebesar 71,85\% berarti efektif dan EPP sebesar 56,48\% berarti cukup efektif, pada aspek perubahan perilaku EP sebesar 74,60\% berari efektif sedangkan EPP sebesar 53,10\% yang berarti cukup efektif.

Kata kunci : Perubahan Perilaku, Kelompok Ngudi Luhur, Pupuk Organik Cair

\section{BEHAVIOR CHANGE OF FARMERS ON THE UTILIZATION OF COW URINE AS LIQUID ORGANIC FERTILIZERS AT NGUDI LUHUR FARMER GROUP IN PANDEAN VILLAGE NGABLAK DISTRICT}

Iing Damayanti, Sunarsih, Sucipto

\begin{abstract}
The activity held at Ngudi Luhur Farmers Group, Pandean Village, Ngablak District on March 5, 2018 until April 30, 2018. This extension evaluation aims to determine the behavioral changes of Ngudi Luhur Farmer Group members Pandean Village Ngablak District on the utilization of cow urine as liquid organic fertilizers, and to determine the Effectiveness of Counseling (EP) on the use of cow urine as a liquid organic fertilizer, as
\end{abstract}


well as to determine the Effectiveness of Behavior Change (EPP) on the use of cow urine as a liquid organic fertilizer.

The respondents of the research were 30 farmers selected by using sensus method. The observed variables such as knowledge, attitudes, and skills of pre-test results (before) and post test (after) do counseling. The analysis is comparative descriptive that comparing changes in the behavior members of farmer group before and after extension is measured using a Likert scale.

The study showed that after counseling was Ngudi Luhur Farmer Group on aspects of knowledge in the know category with an average of 37.40, attitude aspect in the agree category with an average of 26.70 , aspects of skill in the skilled category with an average of 14.37 and changes its behavior prior to the extension in the low category amounted to 48.43 and after the extension into 78.46 in the high category,

The conclusion that behaviour changes of farmers to use cow urine as a liquid organic fertilizer obtained 78.46 value included in the high category, and Effectiveness of Counseling (EP) was $74.60 \%$ categorized as effective, while Effectiveness of Behavior Change (EPP) was $53.10 \%$ included in the quite effective category.

Keywords : Behavior Change of Farmer, Ngudi Luhur Farmer Group, Liquid Organic Fertilizer.

\section{PENDAHULUAN}

\section{A. Latar Belakang}

Desa Pandean terletak di Kecamatan Ngablak yang memiliki potensi budidaya ternak sapi berjumlah 987 ekor dan mampu menyediakan pakan alami yang melimpah karena merupakan dataran tinggi. Salah satu limbah ternak yang dikenal oleh masyarakat adalah pupuk organik cair (POC) karena kandungan unsur hara yang terkandung didalamnya, terutama kandungan nitrogen, fosfor dan kalium. Urin sapi adalah sisa sekresi dari metabolisme yang dilakukan oleh sapi, seekor sapi dewasa dalam usaha peternakan mampu menghasilkan urin sebanyak 8 liter/hari, sehingga bagi industri peternakan urin merupakan komoditas yang sangat potensial untuk menghasilkan nilai ekonomis yang tinggi (Irfan, 2013).

Kelompok tani di desa tersebut belum memanfaatkan limbah ternaknya secara optimal kususnya limbah urin sapi, sebagian petani menggunakan urin sapi secara langsung, dimana sebenarnya penggunaan urin sapi secara langsung kurang baik karena dapat menyebabkan tanaman tersebut menjadi layu karena belum mengalami proses fermentasi, sebaiknya urin sapi diproses terlebih dulu untuk menjadi pupuk organic cair. Petani lebih memilih menggunakan pupuk anorganik yang lebih praktis dan cepat digunakan tanpa memikirkan efek samping kedepanya.

Dengan belum dimanfaatkan limbah urin tersebut petani sebagai pelaku utama perlu didorong agar dapat meningkatkan pengetahuan, sikap dan keterampilan peternak sehingga terciptanya kesejahteraan. Untuk itu perlu diketahui bagaimana perubahan perilaku peternak meliputi aspek pengetahuan, sikap dan keterampilan sebelum dilakukan penyuluhan dan sesudah penyuluhan. Berdasarkan latar belakang tersebut maka penulis akan melakukan penelitian dengan judul "Perubahan Perilaku Petani terhadap pemanfaatan urin sapi sebagai pupuk organik cair di kelompok tani budi luhur Desa Pandean Kecamatan Ngablak Kabupaten Magelang". 


\section{B. Rumusan Masalah}

1. Belum diketahui sejauh mana tingkat perubahan perilaku anggota Kelompok Tani Ngudi Luhur Desa Pandean Kecamatan Ngablak terhadap pemanfaatan urin sapi sebagai pupuk organik cair.

2. Belum diketahuinya efektifitas penyuluhan (EP) tentang pemanfaatan urin sapi sebagai pupuk organik cair

3. Belum diketahuinya efektifitas perubahan perilaku (EPP) tentang pemanfaatan urin sapi sebagai pupuk organik cair

\section{Tujuan}

1. Untuk mengetahui perubahan perilaku petani anggota Kelompok Tani Ngudi Luhur Desa Pandean Kecamatan Ngablak terhadap pemanfaatan urin sapi sebagai pupuk organik cair.

2. Untuk mengetahui efektifitas penyuluhan (EP) tentang pemanfaatan urin sapi sebagai pupuk organik cair

3. Untuk mengetahui efektifitas perubahan perilaku (EPP) tentang pemanfaatan urin sapi sebagai pupuk organik cair

\section{TINJAUAN PUSTAKA}

\section{A. Kerangka Pikir}

Perubahan perilaku adalah proses yang terjadi sejak pertama kali seseorang mendengar hal yang baru sampai orang tersebut mengubah perilaku (menerima, menerapkan, menggunakan) hal baru tersebut (ibrahim dkk, 2003). Tingkat perubahan perilaku dianalisis dengan menggunakan analisis deskriftif comperatif yaitu membandingkan perubahan perilaku anggota kelompok tani sebelum penyuluhan dan sesudah penyuluhan. Perubahan perilaku terhadap Tingkat kemampuan dilihat dengan melihat perbedaan pra test dan post test dari aspek pengetahuan, sikap dan keterampilan, dampak kegiatan penyuluhan dengan rancangan sebelum dan sesudah, dengan satu kelompok atau one group pra test-post test, Suryabrata (2005). Alur pikir dalam penelitian ini dapat dilihat pada Gambar 1.

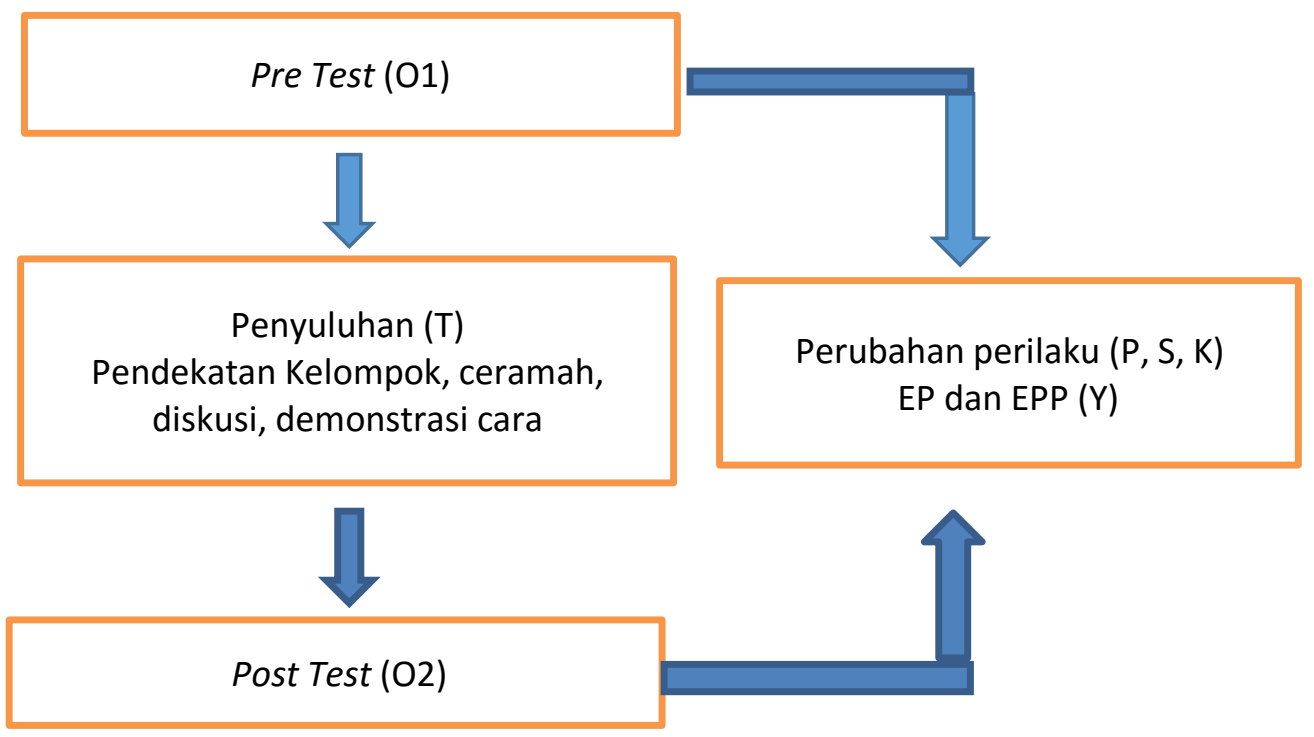

Gambar . Skema Kerangka Pikir 


\section{METODOLOGI}

\section{A. Lokasi dan Waktu}

Kegiatan Penelitian ini dilaksanakan selama 2 bulan dimulai pada tanggal 5 Maret 2018 sampai tanggal 30 April 2018, Tempat pelaksanaan di Kelompok Tani Ngudi Luhur, Desa Pandean Kecamatan Ngablak. Desa Pandean merupakan desa yang terletak di kaki Gunung Merbabu dengan ketinggian $1350 \mathrm{~m}$ dpl dan suhu berkisar $17^{\circ} \mathrm{C}$.

\section{B. Bahan dan Alat}

\section{Alat}

Alat yang digunakan dalam kegiatan penyuluhan antara lain alat tulis, kamera, Laptop, proyektor, kuesioner dan Leaflet, Sedangkan alat bantu untuk demonstrasi cara antara lain adalah : Timbangan, blender, drum, gelas ukur, pisau, telenan, dan Ember

\section{Bahan}

Bahan yang digunakan untuk kegiatan penyuluhan adalah kertas hvs, media penyuluhan dan untuk demonstrasi cara dalam kegiatan penyuluhan antara lain limbah urin sapi, EM-4, empon-empon (kunyit, jahe, lengkuas, temulawak, sambiroto) sebanyak $1 \mathrm{~kg}$ dan molasses.

\section{Rancangan atau Desain}

Rancangan penelitian yang dilakukan adalah melakukan pengukuran tingkat perubahan perilaku, variable yang diamati yaitu pengetahuan, sikap, dan keterampilan petani terhadap pemanfaatan urin sapi sebagi pupuk organic cair di Kelompok Tani Budi Luhur Kecamatan Ngablak Kabupaten Magelang dengan responden berjumlah 30 orang, dengan langkah sebagai berikut : a) Membuat lembaran persiapan menyuluh (LPM) dan membuat sinopsis yang berisi tentang pembuatan pupuk organic cair dan membuat media penyuluhan dalam bentuk leaflet, b) sebelum dilakukan penyuluhan membuat daftar kuisioner terlebih dahulu untuk mengukur perubahan perilaku responden, c) melakukan uji validitas dan reliabilitas kuisioner yang akan digunakan, Langkahlangkah dalam melakukan uji validitas kuisioner yaitu dengan cara wawancara langsung dengan responden sebanyak 16 orang selanjutnya mengolah data hasil wawancara dengan program SPSS 16 untuk uji validitas d) setelah kuisioner diuji validitas dan reliabilitas kemudian kuisioner diujikan dengan 30 responden sebelum melakukan penyuluhan (Pra test), e) melaksanakan penyuluhan dikelompok tani budi luhur, f) Kegiatan (Pos test yaitu pengambilan data setelah 2 minggu sesudah dilaksanakan penyuluhan dengan wawancara petani yang berjumlah 30 responden mengenai pemanfaatan urin sapi sebagai pupuk organic cair), g) Rekapitulasi data tingkatan atau jenjang setiap gejala di ukur dengan menggunakan skala likert yaitu perubahan perilaku sangat tinggi (5), tinggi (4), cukup tinggi (3), sedang (2) dan rendah (1), dimana daftar pertanyaan merupakan alternatif pengungkapan permasalahan yang di dasarkan pada variabel yang diamati. Perubahan perilaku dilihat dengan membandingkan hasil pre test dan post test dari aspek pengetahuan, sikap, dan keterampilan

\section{Populasi dan Sampel}

Metode pengambilan sampel yang digunakan adalah dengan metode sensus yaitu teknik pengambilan sampel secara keseluruhan dari jumlah anggota kelompok tani Budi Luhur yang jumlah anggotanya 30 orang. Menurut Ifa (2007), bahwa apabila populasi lebih dari seratus orang, dapat diambil sampel sebanyak 10-25 
persen dan apabila populasi sama atau kurang dari seratus orang harus diambil semua.

\section{E. Data dan Sumber data}

Sumber data yang akan digunakan pada pengkajian ini adalah : 1 . Data primer yaitu data yang diperoleh langsung dari objek penelitian melalui pengamatan langsung (observasi) dan wawancara langsung dengan responden, dimana responden adalah anggota Kelompok Tani Budi Luhur. 2. Data sekunder yaitu data yang diperoleh dari instansi-instansi terkait seperti BPP yang memiliki data sebagai data pendukung yang berhubungan dengan permasalahan akan dikaji seperti keadaan umum lokasi yang meliputi gambaran lokasi, sejarah singkat dan lain-lain.

\section{F. Analisis Data}

Tingkat perubahan perilaku analisis yang digunakan adalah analisis deskriftif comperatif yaitu membandingkan perubahan perilaku anggota kelompok tani sebelum penyuluhan dan sesudah penyuluhan. Perubahan perilaku terhadap Tingkat kemampuan dilihat dengan melihat perbedaan pra test dan post test dari aspek pengetahuan, sikap dan keterampilan, dampak kegiatan penyuluhan dengan rancangan sebelum dan sesudah, dengan satu kelompok atau one group pra test-post test, Suryabrata (2005). Rancangan ini dapat digambarkan $\left(\mathrm{O}_{1}-\mathrm{T}-\mathrm{O}_{2}\right)$ dengan penjelasan sebagai berikut :

$\mathrm{O}_{1}$ : Pra test, untuk mengukur pengetahuan, sikap dan keterampilan sebelum kegiatan penyuluhan.

$\mathrm{T}$ : Treatment, kegiatan penyuluhan.

$\mathrm{O}_{2}$ : Post test, untuk mengukur pengetahuan, sikap dan keterampilan setelah diadakan penyuluhan.

Kegiatan yang dilakukan yaitu data yang telah direkap dan ditabulasikan kemudian diolah, disusun, dianalisis berdasarkan hasil pretest dan posttest ditentukan kategori penilaian dengan menggunakan skala likert. Skala likert adalah jumlah skor maksimal dari setiap pertanyaan variabel diukur dkurang jumlah skor minimal, kemudian selisihnya dibagi lima. Cara menganalisis data adalah dengan cara:

a. Nilai minimal $=$ nilai terendah $\mathrm{x}$ jumlah pertanyaan

b. Nilai maksimal $=$ nilai tertinggi $x$ jumlah pertanyaan

c. Jarak interval = $\underline{\text { (nilai maksimal-nilai minimal }}$ jumlah kriteria

d. Pembuatan Garis Kontinum

\section{HASIL DAN PEMBAHASAN}

\section{Aspek Pengetahuan}

Jika digambarkan dalam garis

kontimum sebagai berikut:

Nilai minimal $=1 \times 10=10$

Nilai maksimal $\quad=5 \times 10=50$

Jarak interval $=\frac{(50-10)}{5}=8$ 


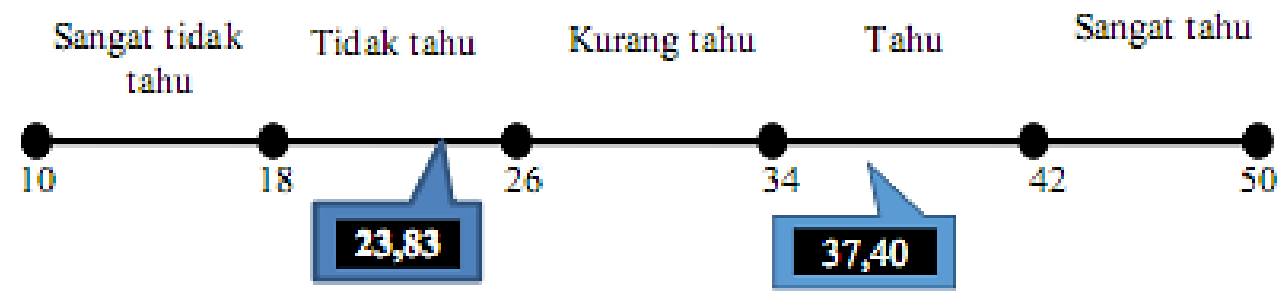

Gambar 2. Garis Kontinum Aspek Pengetahuan

Berdasarkan garis kontinum diatas menunjukkan bahwa adanya peningkatan pengetahuan petani sebelum dan sesudah penyuluhan dari tidak tahu sebesar 23,83 menjadi tahu sebesar 37,40 . Hal ini sesuai dengan pendapat Mardikanto (2009), bahwa dalam penyampaian penyuluhan tidak hanya dengan lisan, tetapi juga perlu alat bantu atau alat peraga agar materi lebih mudah diterima dan diserap serta lebih mengesankan.

\section{Aspek Sikap}

Jika digambarkan dalam garis kontimum sebagai berikut :

Nilai minimal $=1 \times 7=7$

Nilai maksimal $\quad=5 \times 7=35$

Jarak interval $=\frac{(35-7)}{5}=5,6$

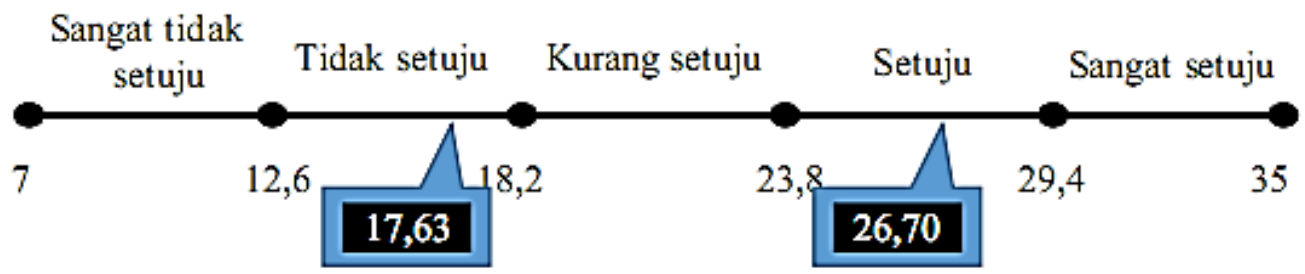

Gambar 7. Garis Kontinum Aspek Sikap

Berdasarkan garis kontinum diatas menunjukkan bahwa adanya peningkatan dari tidak setuju sebesar 17,63 menjadi 26,70. Hal ini disebabkan oleh kesadaran responden akan pentingnya pupuk organik cair sehingga petani mau membuat pupuk organik cair, hal ini sesuai dengan pendapat Wiratmadja (1995) bahwa perubahan sikap tidak secara tiba-tiba tetapi memerlukan waktu yang agak lama yang dinamakan proses mental atau proses adopsi, yaitu dari tahap menyadari, minat, menilai, mencoba dan akhirnya mengadopsi inovasi baru

\section{Aspek Keterampilan}

Jika digambarkan dalam garis kontimum sebagai berikut:

Nilai minimal $=1 \times 4=4$

Nilai maksimal $=5 \times 4=20$

Jarak interval $=\frac{(20-4)}{5}=3,2$ 


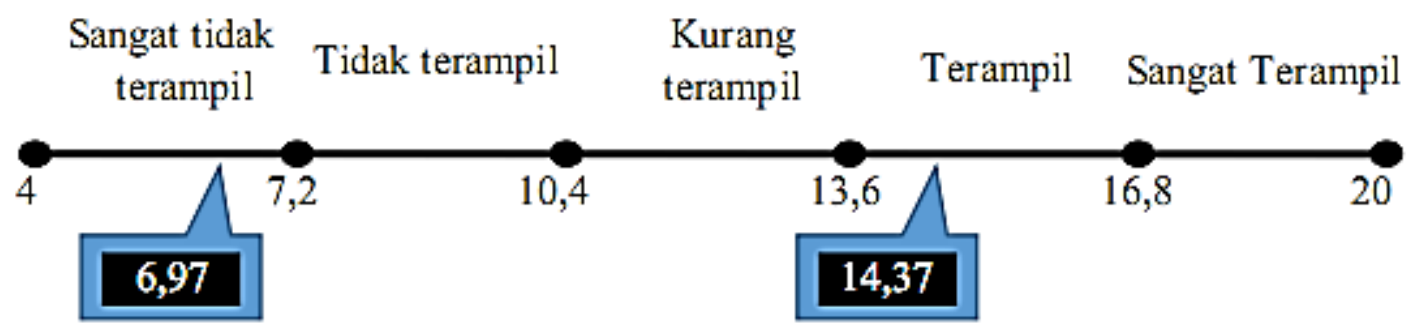

Gambar 8. Garis Kontinum Aspek Keterampilan

Berdasarkan garis kontinum diatas menunjukkan bahwa adanya peningkatan keterampilan responden sebelum dan sesudah penyuluhan dari sangat tidak terampil menjadi terampil. Sesuai dengan pendapat Mardikanto (2009) yang menyatakan bahwa materi penyuluhan yang akan disampaikan oleh seseorang penyuluh harus mengacu kepada kebutuhan yang telah dirasakan oleh masyarakat penerima manfaat.

\section{Aspek Perubahan Perilaku}

Jika digambarkan dalam garis

kontimum sebagai berikut :

Nilai minimal $=1 \times 21=21$

Nilai maksimal $\quad=5 \times 21=105$

Jarak interval $=\frac{(105-21)}{5}=16,8$

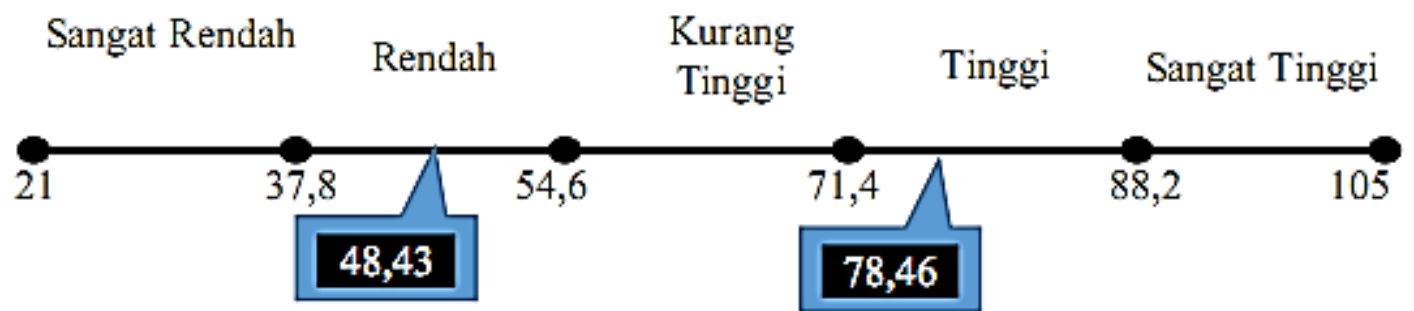

Gambar 9. Garis Kontinum Aspek Perubahan Perilaku

Berdasarkan garis kontinum diatas menunjukkan bahwa adanya peningkatan perubahan perilaku $\mathrm{P}, \mathrm{S}, \mathrm{K}$ responden sebelum dilakukan penyuluhan sebesar 48,43 dan sesudah penyuluhan sebesar 78,46 dengan kategori tinggi. Hal ini disebabkan oleh beberapa factor seperti umur, tingkat pendidikan, materi dan metode penyuluhan.

\section{Evaluasi Penyuluhan}

Hasil perhitungan dari seluruh aspek (pengetahuan, sikap, keterampilan) evaluasi penyuluhan tentang pembuatan pupuk organik cair dapat dilihat pada Tabel dibawah ini : 
Tabel 15. Hasil Perhitungan Efektivitas Penyuluhan dan Efektivitas Perubahan Perilaku

\begin{tabular}{llllccr}
\hline \hline Aspek & Pre Test & Post Test & EP $(\%)$ & Keterangan & EPP (\%) & Keterangan \\
\hline Pengetahuan & 23,83 & 37,40 & 74,80 & Efektif & 51,85 & Cukup efektif \\
Sikap & 17,63 & 26,70 & 76,28 & Efektif & 52,21 & Cukup efektif \\
Keterampilan & 6,97 & 14,37 & 71,85 & Efektif & 56,48 & Cukup efektif \\
Perilaku & 48,43 & 78,47 & 74,60 & Efektif & 53,10 & Cukup efektif \\
\hline
\end{tabular}

Sumber : Data Terolah, 2018

Berdasarkan data diatas menunjukkan bahwa nilai perubahan perilaku (pengetahuan, sikap, keterampilan) Efektivitas Penyuluhan (EP) sebesar $74,60 \%$ yang berarti bahwa penyuluhan yang dilakukan efektif sedangkan nilai untuk Efektivitas Perubahan Perilaku (EPP) sebesar $53,10 \%$ yang berarti perubahan perilaku responden cukup efektif. Hal ini sesuai dengan pendapat Ginting (1993) dengan kriteria) a) $\leq 33,3 \%$ dinyatakan kurang efektif , b) $33,3 \%-66,6 \%$ dinyatakan cukup efektif c) $\geq 66,6$ dinyatakan efektif.

\section{SIMPULAN DAN SARAN}

\section{A. Simpulan}

Dalam melakukan penelitian ini dapat disimpulkan sebagai berikut :

1. Perubahan perilaku petani anggota Kelompok Tani Ngudi Luhur Desa Pandean Kecamatan Ngablak terhadap pemanfaatan urin sapi sebagai pupuk organik cair sebelum dilakukan penyuluhan kategori rendah setelah dilakukan penyuluhan menjadi kategori tinggi.

2. Dapat mengetahui efektifitas penyuluhan (EP) tentang pemanfaatan urin sapi sebagai pupuk organik cair memperoleh nilai $74,60 \%$ yang berarti penyuluhan tersebut efektif.

3. Dapat mengetahui efektifitas perubahan perilaku (EPP) tentang pemanfaatan urin sapi sebagai pupuk organik cair sebesar 53,10\% yang berarti cukup efektif.

\section{B. Saran}

Saran yang dapat disampaikan setelah penelitian ini, antara lain:

1. Bagi kelompok tani agar lebih aktif dan produktif, Selain itu agar tetap meningkatkan kualitas sumber daya manusia dan menjalin kerjasama yang baik dengan penyuluh setempat, instansi pemerintah atau lembaga terkait

2. Perubahan perilaku petani dapat ditingkatkan melalui pengetahuan, sikap dan keterampilan melalui pembinaan, pelatihan dan pendampingan.

\section{DAFTAR PUSTAKA}

Ginting. 1993. Pokok Pikiran Penerapan Metode Penelitian Sosial dalam Kuliah Kerja Lapang. Universitas Brawijaya Malang.

Ibrahim, J.T, A. Sudiyono dan Harpowo. 2003. Komunikasi dan Penyuluhan Pertanian. Bayu Media Publishing. Malang.

Ifa. 2007. Penelitian tentang Persepsi Petani terhadap Inovasi untuk Menggunakan Pupuk Kompos Kotoran Ternak Produk P4s Bumi Lestari Sragen (Kasus Petani di Desa Gondang, Kecamatan Gondang, Kabupaten Sragen). Institut Pertanian Bogor. Hal: 28. 
Irfan. 2013. Jurnal Penelitian Aplikasi

Limbah Cair Sebagai Pupuk

Organik Cair Pada Tanaman Jagung.

Universitas Riau: Riau

Mardikanto. 2009. Sistem Penyuluhan

Pertanian. Sebelas Maret University

Pres. Suryakarta

Suryabrata.S. 2005. Definisi Respon PT.

Raja Grafindo Persada Jakarta.

Wiratmadja. 1995. Poko-Pokok Penyuluhan

Pertaniaan. Universitas Brawijaya.

Malang. 